\title{
The Relationship Between Intelligence and Psychological Well-Being in Incoming College Students
}

\author{
Clifton J Wigtil ${ }^{*}$ and Gregg R Henriques
}

*Correspondence: cwigtil@yahoo.com

James Madison University, Harrisonburg, Virginia, USA

\section{焦 Springer}

\begin{abstract}
Background: This study investigated the relationship between intelligence and psychological well-being in young adults. Contradictory findings are presented about the relationship between intelligence and PWB in children and adolescents, and qualitative findings by Lovecky (J Couns Develop 64:572-575, 1986) in adults. For young adults, the authors predicted positive linear relationships between intelligence and PWB dimensions of Environmental Mastery, Autonomy, Personal Growth, Purpose in Life, and a curvilinear relationship between intelligence and the PWB dimension of Positive Relations with Others.

Methods: These hypotheses were tested on a sample of 3,829 incoming first-year students at a large university using multiple regression of SAT scores (The College Board, SAT Reasoning Test, 1926-2005) and scores of these dimensions on a 54-item version (van Dierendonck, Personal Individ Differ 36:629-643, 2004) of Ryff's (J Personal Soc Psychol, 57(6):1069-1081, 1989) Scales of Psychological Well-Being.

Results: Results supported a curvilinear relationship between SAT Verbal and Positive Relations with Others; significant relationships between SAT Math and Purpose in Life and Personal Growth were also discovered, but in the negative direction.
\end{abstract}

Conculsions: Limitations, possible reasons for data trends, and potential application of results to university policy are discussed.

Keywords: Intelligence, Positive psychology, Psychological well-being

\section{Introduction}

Intelligence and well-being are two of psychology's most well-known constructs. Yet, although early research explored the relationship between these two constructs, the relationship remains nebulous, and, in general, few large scale quantitative studies have been conducted. Most research that has been done has explored the relationship between intelligence and mental disorders and dysfunction. However, as highlighted by the increase in research and interest in positive psychology (Seligman and Csikszentmihalyi 2000), there is much more to mental health than distress and dysfunction. Ryff (1989) created a model of one aspect of positive psychology, psychological well-being (PWB), which consists of six domains: "Self-Acceptance," "Positive Relations with Others," "Autonomy," "Environmental Mastery," "Purpose in Life," and "Personal Growth." Self-acceptance referred to an

(c) 2015 Wigtil and Henriques. This article is distributed under the terms of the Creative Commons Attribution 4.0 International License (http://creativecommons.org/licenses/by/4.0/), which permits unrestricted use, distribution, and reproduction in any medium, provided you give appropriate credit to the original author(s) and the source, provide a link to the Creative Commons license, and indicate if changes were made. 
affirming outlook on his or her life; Positive (and secure) Relations with Others; Autonomy, the extent to which one operates independently and does not conform to public norms; Environmental Mastery, engaging in and skillfully controlling one's environment; Purpose in Life, the extent to which one has aims and a general course to their actions; Personal Growth, the extent to which one actualize and improve oneself.

\section{Background}

Some researchers have concluded that no relationship between subjective well-being and intelligence exists; for example, Gottfredson (2008) concluded that intelligence "does not correlate with happiness (subjective well-being)"; however, less research has been done on psychological well-being and its relationship to intelligence. The purpose of the study was to explore the relationship between these dimensions of well-being and intelligence in incoming college students. Rinn and Plucker (2004) noted that further study of young adults of high ability is of special interest to higher educational institutions and their attempts to improve both scholastic and non-scholastic opportunities. This age marks the beginning of a new milestone in a person's development, a transition out of childhood and into adulthood. Although some interest has been paid to the development of some of these dimensions of college students' well-being (e.g., Astin and Astin 2010, studied purpose in life from a spiritual perspective as "spiritual quest"), a review of the extant literature could find none relating this well-being to intelligence in this population. Therefore, the relationship between these constructs in younger (child/ adolescent) and older (adult) populations are reviewed.

\section{Prior Investigations of a Possible Link Between Well-Being and Intelligence in Children}

Intelligence has often been studied in the context of gifted education, as it is one means of identifying children as gifted (Davis and Rimm 2004, p. 86). One early line of research in gifted education into the relationship between high intelligence and mental health suggested either no difference or that intelligent children have more robust mental health. Terman (1925) explored the psychological characteristics of a group of high intellectual ability group ${ }^{\mathrm{a}, \mathrm{b}}$ of 643 elementary and middle-school aged children from California, with a control group. The former group had a lower level of social play, was more likely to favor older friends, and was rated by teachers to have more positive interpersonal characteristics, goal-directed behavior, and creativity.

Gallucci (1988) explored rates of psychopathology in 83 extremely intelligent Louisianan adolescents ages $12-16$ (defined as at least the 99.2nd percentile). ${ }^{\mathrm{c}}$ Problematic behaviors were identified through the Child Behavior Checklist (CBCL; Achenbach, 1991). Gallucci also compared the rate of psychopathology between 31 children with IQs between the 99.2nd and 99.6th percentiles ${ }^{\mathrm{d}}$ and 18 children with IQs above the 99.96th percentile. ${ }^{\mathrm{e}}$ Neither comparison yielded significant differences on CBCL scores, suggesting no PWB-intelligence relationship.

Richards et al. (2003) studied Australian adolescent students of normal and high intelligence with respect to their interpersonal, intrapersonal, and environmental activity as measured by the Behaviour Assessment System for Children (BASC; Reynolds and Kamphaus 1992), which uses ratings from children, parents, and teachers on these aforementioned domains. The authors contrasted scores on two groups, those at or above the 96th 
percentile ${ }^{\mathrm{f}}$ on IQ tests and those who did not. Ratings across the BASC subscales indicated either more or equally adaptive parent and teacher ratings for the intelligent students in domains of emotions and behavior. Together, this line of literature suggested, a positive relationship between intelligence and Ryff's Autonomy, Positive Relations with Others, Environmental Mastery, Purpose in Life, and Personal growth dimensions of PWB.

Grossberg and Cornell (1988) noted that this line of research is contradicted by another line of findings, beginning with Hollingworth (1942), who detailed several case studies of children above 180 IQ (original Stanford-Binet, ratio IQ). She found such children were generally more autonomous but had difficulties in normal social development (suggesting lower levels on Ryff's Positive Relations with Others). To Hollingworth, these difficulties went hand in hand with the extremity of their intelligence, an observation she generalized to a lower limit just above 160 IQ (original Stanford-Binet). ${ }^{g}$ She believed that the apparent difficulty in highly intelligent children's social functioning had to do with their cognitive content being different and rare, in contrast to their age-mates' Given that IQ scores become rarer in curvilinear fashion as they deviate from the mean, this suggests a curvilinear relationship between intelligence and social functioning. ${ }^{\text {h }}$

Affirming Hollingworth's characterization, Kline and Meckstroth (1985) argued that very intelligent children may experience psychological difficulties. Basing their conclusions on their clinical psychological and school consulting experience, they argued that such children ${ }^{i}$ are in jeopardy of cognitive, affective, and interpersonal issues, which are in proportion to the level of intelligence. They also argued that such issues may be related to the others' inability to comprehend these children, and coping with the hopes that their elders have for them.

Paralleling this view, Betts (1986) argued that school programs for intelligent (he did not suggest a cutoff) children need to address their special needs of affective and interpersonal development. Many of these needs overlap with some of Ryff's dimensions of well-being, such as "awareness, understanding, and acceptance of self...and others...and interpersonal skills". According to Betts, intelligent children also have needs related to original ideation and working out one's difficulties, unwinding, and optical imagination, and maintaining supportive milieus.

Neihart (1999) exhaustively reviewed empirical literature with respect to the relationship between intelligence and well-being, and agreed with Richards et al. that the empirical evidence supports the view that high intelligence either has no effect or has a beneficial factor to psychological well-being. She included in well-being such components as a lack of deviant behavior, depression, anxiety, and psychiatric disorders, as well as the (healthy) presence of social competence. Nonetheless, in general Neihart argued that overall the literature supports the first line of research (that highly intelligent children are generally as well or better adjusted than the general population).

However, Neihart also cited research supporting the idea that highly intelligent children experience social difficulty. Specifically, she cited Dauber and Benbow's (1990) study comparing students achieving at least the 99.99th percentile on either the verbal or mathematics component of the SAT (College Board, 1926-2005) vs. those who only met a lower standard, the 95th percentile on one component. The authors found that highly intelligent students rated themselves as less socially adept, more inhibited, and more introverted than their counterparts of above-average intelligence. 
More recently, Gross (2004), in her research on 15 very intelligent children (6-13 years at or above the 99.997th percentile of intelligence'), finding that such children were that they generally evaluated themselves higher in scholastic ability, but lower interpersonally. Unfortunately, the children in her research, as in Hollingworth's, were referred by parents, teachers, and psychologists responding to advertising for the study, thus potentially creating a sampling bias.

Vialle et al. (2007) compared 65 intelligent adolescents (defined in this study as those in the 90th percentile of each of two tests of reading and mathematical achievement) and a comparison group of normal intelligence on self-reported social measures. The intelligent adolescents in Vialle et al's study rated themselves higher on measures of sadness (measured by the PANAS-X; Watson and Clark 1991) and lower on the self-reported set of social support variables (quantity and quality measured by the Social Support Questionnaire; Sarason et al. 1983). Teachers, however, rated that the intelligent adolescents as less prone to affective disturbance and had higher general adjustment relative to students of normal intelligence. Thus, while teachers reported that these students exhibited little maladaptive behavior, the students themselves reported that they have poor social support.

Norman et al. (1999) compared students within the intelligence range of the 84th98th percentiles $^{k}$ to those above the 98 th percentile, ${ }^{1}$ and then a separate comparison of students ranging from 84th to 99.4th percentiles with those above the 99.4th. ${ }^{\mathrm{m}}$ The dependent variables were several social subscales of a self-report instrument, as well as two separate measures, one of "emotional autonomy" from their parents and the other of anxiety. The students were recruited from summer programs for intelligent students. The authors did not observe significant differences between the groups in either comparison.

Thus, a pattern emerges with respect to Ryff's well-being and high intelligence in children and adolescents. Some literature suggests that highly intelligent children appear to have higher levels of Ryff's Autonomy (though adult expectations may derail this to an extent; Betts 1986), Environmental Mastery, Personal Growth, Positive Relations with Others, and Purpose in Life. This would possibly correspond to the application of superior cognitive ability to manage one's own affairs and master one's immediate environment, and some theoreticians have linked constructs similar to these PWB dimensions, such as resilience, to intelligence (e.g., Bland and Sowa 1994). Given the affective comorbidity associated with mental retardation mentioned earlier, this line of research suggests a general relationship between intelligence and PWB. On the other hand, the second line of research and theory, suggests that intelligence, as it becomes more extreme, may be a hindrance to one's level of Positive Relations with Others.

Together, these studies and perspectives appear to be contradictory with respect to a potential relationship between PWB and intelligence. There are some possible reasons for this. First, some of the studies in this review suffered methodological limitations. After the publication of some of these studies, MacCallum et al. (2002) suggested that the use of ANOVA and t-tests rather regression on continuous variables (such as intelligence) generally lowers the statistical power of the analysis. Next, these studies did not always focus on PWB (for example, the CBCL in Gallucci's study focuses primarily on problematic behavior, not mental wellness), or intelligence (e.g., Vialle et al. used achievement tests) per se. Nonetheless, it remains possible that no relationship exists between these constructs, which may be indicated by the nonsignificant findings of Norman et al. 
Distal Causes of Intelligence-Based Differences in Psychological Well-Being in Adults

Some empirical studies have explored the relationship between intelligence and PWB in adulthood quantitatively. Parker et al. (2008), for example, found a relationship between a correlate of intelligence (brain size) and apparent indicators of psychological well-being (e.g., "feeling useful"). In a sample of schizophrenic adults, Lysaker et al. (2001) found small correlations between tests of specialized cognitive abilities and the well-being subtest score of the Attitude Questionnaire. Plescia-Pikus et al. (1988) found higher intelligence in both adult children of alcoholics who reported high well-being and controls, compared to adult children of alcoholics who reported low well-being.

These studies did not reflect the population of interest to this study, the general population of adults, nor did these studies explicitly consider well-being in Ryff's theoretical framework. A literature review of general characteristics of adults with above-average intelligence instead finds mostly observational findings, with few quantitative studies of well-being. Of the former, Lovecky's (1986) discussion of intelligent adults and wellbeing reflects most of the literature on this subject, which will provide the theoretical basis on adults for the hypotheses in the present study.

Lovecky posited social and emotional needs of intelligent adults based on her (1) discussions with gifted adults and observations in counseling them, and (2) extending previous work with gifted and creative children by Paul Torrance (1962). She believed that intelligent adults are marked by intensity of five qualities: "divergency, excitability, sensitivity, perceptivity, and entelechy," of which all but the second seem relevant to dimensions of PWB.

Lovecky argued that one's divergency (of thought) makes adults "highly independent", who "find creative solutions to a wide variety of problems, including interpersonal problems", but also creates "difficulty in situations where group consensus is important". To the extent that intelligence correlates with specialized cognitive abilities, greater intelligence would improve the ability to think divergently. Sensitivity, which Lovecky described as "depth of feeling that results in a sense of identification with others", creates personal bonds with others and a drive to improve society. However, she held that this same sensitivity could lead to being dismissive of another's personal requirements if they seem shallow, and that others could hide problems from intelligent friends, for fear of losing room for their own feelings in the face of such high emotional sensitivity. Lovecky observed that intense intrapersonal and interpersonal perceptivity allows intelligent adults a greater degree of objectivity in their relations with others; at the same time, however, others may fear being well-perceived. This same perceptivity allows intelligent adults to grasp the essence of a subject. Additionally, she believed that intelligent adults' perceptivity clarifies their own desires. With respect to intelligent adults' unusually high entelechy, ("motivation, inner strength, and vital force directing life and growth"), Lovecky suggested that others may respond to this desire with a heightened entelechy of their own, dependent on the former's example and support, creating tension for the intelligent adult between personal growth and supporting others.

Why might the qualities Lovecky proposed exist in intelligent adults? Luthar et al. (1992) suggested that a positive relationship between intelligence and the number of cognitive schemas produced by an individual would lead the more intelligent to categorize their experiences into a greater number of existing schemas, leading to better 
adjustment. This may explain divergency of thought (e.g., more schemas allowing for multiple ways to interpret and synthesize information), but this model alone, however, does not appear to be sufficient to explain other qualities (e.g., sensitivity) observed by Lovecky.

Lovecky thus hypothesized about prominent qualities in intelligent adults that affect their social and emotional functioning, and would seem to have both positive and negative relationships with Ryff's PWB, and these qualities appear to be somewhat supported by the literature. Unfortunately, she gave no indication of the percentiles of intelligence at which these qualities would emerge. Nonetheless, each of these qualities appears to generally have a positive relationship with intelligence in adults, except for social functioning, in which a curvilinear relationship to intelligence seems indicated by the literature.

Of the qualities that Lovecky mentioned in intelligent adults, each suggests a relationship between intelligence and at least one of Ryff's dimensions of PWB. Divergency and entelechy suggest a positive relationship between intelligence and Autonomy ("resistance to enculturation"). Perceptivity and entelechy suggest a positive relationship between intelligence and Environmental Mastery. Entelechy suggests a positive relationship between intelligence and Personal Growth. Sensitivity and perceptivity suggest a positive relationship between intelligence and Purpose in Life. Sensitivity, divergency, perceptivity, and entelechy suggested a curvilinear relationship between intelligence and Positive Relations with Others.

\section{Purpose of the Current Study}

The present study examines in a sample of young adults the relationship between intelligence and those dimensions of Psychological Well-Being which previous research suggests may be related to it. It is desirable to examine the relationship in young adults between intelligence and PWB using quantitative methods with larger samples that are more sensitive to subtle effects. A literature review of older and younger populations revealed studies that yielded positive, negative, and nonsignificant relationships, yet did not include curvilinear effects (possibly due to smaller sample sizes). Additionally, it may be helpful to investigate the construct of intelligence as a continuous phenomenon, rather than a categorical phenomenon yielding groups of typical ability, moderate giftedness, or high giftedness.

Next, it is desirable to extend findings with respect to intelligence and PWB from a developmental perspective. This study sought to answer whether related research on the population of intelligent children and adolescents extend in a logical manner to young adults. It may be that results are similar to previous results found for adolescents, or instead change for some reason during the transition from adolescence to young adulthood. Likewise, results from this study could be informative based on whether they align with prior observations of intelligent adults.

This study was also conducted for its usefulness to higher education. As mentioned, Rinn and Plucker (2004) note that this specific population is of special interest to higher educational institutions and their attempts to improve "honors", "early entrance", and "personal counseling" programs for intelligent young adults. If a relationship exists between PWB and intelligence, it would suggest the need for these services to be specialized to such students' unique PWB. 
Finally, it is also desirable to determine whether these effects of intelligence, if any, may be replicated in a newer population. Many of the aforementioned studies were conducted some time ago.

The previous research often seemed contradictory, but overall, the literature seemed to suggest a positive relationship between intelligence and psychological well-being. The exception was the dimension of Positive Relations with Others, which generally had positive relationships at elevated levels of intelligence, and negative relationships at extremely high levels of intelligence. Therefore, the following hypotheses were proposed:

H1: Intelligence has a positive relationship with Ryff's Autonomy.

H2: Intelligence has a positive relationship with Ryff's Environmental Mastery.

H3: Intelligence has a positive relationship with Ryff's Purpose in Life.

H4: Intelligence has a positive relationship with Ryff's Personal Growth.

H5: Intelligence has a negative quadratic relationship with Ryff's Positive Relations with Others.

\section{Methods}

Population, Sample, and Procedures

Three samples of incoming first-year (freshmen) students at a central Virginia university were given a series of assessments for the university's annual "assessment days" in 2003, 2004, and 2005, given the weekend before the start of their first classes in the fall term. Assessments were given for the purposes of program improvement and evaluation of the university's general education program (as part of an assessment mandate from Virginia). These assessments are ultimately required for the students to graduate, but student performance on these assessments did not have consequences for the students; there was no extrinsic motivator for student performance on the assessments themselves ("lowstakes"). Students completed an informed consent form before taking the assessments. Invitations were sent to 3,465 students in 2003, 3,351 in 2004, and 3,807 in 2005. Invited students represented a near-census of incoming first-year students at the university.

Students were randomly assigned to take different series of assessments, some of which included the Scales of Psychological Well-Being (see below), referred to as the Well-Being Scale (WBS) on the assessment form. In 2003, 1,089 students took the WBS; 1,387 in 2004; and 1,560 in 2005. Most students' WBS scores could be matched to valid SAT scores, yielding a dataset with 3,829 students across all 3 years, after the removal of two univariate outliers (on the PR and EM subscales) from the data set. No cases were flagged as being multivariate outliers. To test the influence of these outliers, analyses were also run both with and without univariate outliers, which did not appreciably alter the results. For students with available gender data, $65 \%$ were female, $35 \%$ male. The mean age was 18.4 years. Because ethnicity data for the sample itself was not available, such data of first-year students was aggregated across cohorts to establish a close representation of the sample. African-Americans, American Indians, Asian/Pacific Islanders, Caucasians, and Hispanics represented 2.7, 0.2, 5.1, 84.6, and 2.2\% of this aggregate, respectively (ethnicity data was not unavailable for $2.2 \%$ of the cohort). Less than $1 \%$ of students reported being non-resident aliens. Students had mean SAT Math and SAT 
Verbal scores of 552 and 550, respectively, and standard deviations of 69.3 and 71.3, respectively.

\section{Measures}

Scales of Psychological Well-Being (SPWB)

A reduced, 54-item version of Ryff's (1989) SPWB (cf. Kaliski 2006; van Dierendonck 2004) was used as the measure of PWB in this study. On a sample of psychology undergraduate students, van Dierendonck (2004) found Cronbach's $\alpha$ reliability values of 0.83, 0.77, 0.78, 0.77, 0.73, and 0.65 for the Self Acceptance (SA), Positive Relations with Others (PR), Autonomy (AU), Environmental Mastery (EM), Purpose in Life (PL), and Personal Growth (PG) subscales. Of these, Peterson (1994) noted varying extant recommendations for Cronbach's $\alpha$ reliability, but that 0.7 is often considered the minimum acceptable level for reliability.

Out-of-range SPWB scores were recoded as missing (listwise deletion was used in analyses). Theoretically, this measure ought to yield a factor structure of 6 factors, corresponding to Ryff's theorized dimensions of well-being, and also a higher-order factor of overall psychological well-being. Springer and Hauser (2006) find little model fit evidence for a higher-order factor in the 54-item version of the SPWB which was used in the present study, instead finding better fit for models that include a "negatively worded items" factor. Lindfors et al. (2006) found that a six-factor correlated factor model best fit data in the 120-item version, but did not test a negatively worded item factor. More recently, Kaliski (2006) conducted a comprehensive investigation into the factor structure of the 54-item SPWB. In her own research on four samples who had been administered the 54-item version of the SPWB, many of which were included in this study, she championed a seven-factor model, including Ryff's dimensions but also "a negativelyworded method effect factor". However, any structure is only useful to the extent that external validity evidence (i.e., the relationship between scores on the SPWB and external measures) is gathered. Though Strauser et al. (2008) recently found that, together, the subscales of Ryff's 84-item SPWB accounted for significant variance in work personality, vocational identity, and career thoughts, further external validity studies are needed.

\section{SAT (The College Board, 1926-2005)}

Frey and Detterman (2004) reported significant correlations between SAT (known for the sample of their study as the Scholastic Assessment Test) total score (combined verbal and mathematics scores) scores and IQ. Similar results were found by Bilder et al. (2006), in their study of cognitive development in schizophrenia, who reported a correlation of 0.82 between SAT and Full-scale WAIS IQ for their control (non-schizophrenic) group. SAT scores were considered to be a reasonable proxy for intelligence in the sample for the proposed study. In general, the earliest of the SAT scores were chosen in order to not favor those students who took the SAT more than once.

\section{Data Analysis}

The purpose of the large sample was to capture a large number of students with high SAT scores, in order for there to be enough power to detect curvilinear results at the high end of the SAT distribution. Multiple regression was conducted on the following SPWB 
subscales, using SAT component scores (Verbal and Math) as predictors entered into the regression equations simultaneously for five of the SPWB subscales: Autonomy (AU), Environmental Mastery (EM), Purpose in Life (PL), Personal Growth (PG), and Positive Relations with Others (PR); for Positive Relations with Others, squared SAT component scores were also added simultaneously to test for curvilinear effects. To control for Type 1 error across the five hypotheses, alpha was Bonferroni-adjusted to $0.01(=0.05 / 5)$.

Additional exploratory analyses were conducted for three effects. The first exploratory analysis was for the relative contributions of each SAT component score (Verbal and Math). Next, as SAT component scores may moderate one another, the interaction between them was tested for significance. Scatterplots of SAT component scores with each dimension of PWB were visually analyzed to estimate the degree of linearity of the relationship between the components and the dimension of psychological well-being. The third exploratory analysis tested for gender differences in the relationship between SPWB subscale and SAT component scores. These analyses may be useful to practitioners and may aid in future investigations of well-being.

\section{Results}

\section{Regression Assumptions}

All subscale scores associated with hypotheses [Autonomy (AU), Environmental Mastery (EM), Personal Growth (PG), Positive Relations with Others (PR), and Purpose in Life (PL)] were negatively skewed ( -0.104 to -0.835$)$. Kurtosis ranged from -0.300 to 0.502 . Visual analysis of histograms revealed apparent ceiling effects of the Personal Growth, Purpose in Life, and especially the Positive Relations with Others subscales. These dimensions had more negative skewness. While these statistics indicate violations of the normality assumption of multiple regression, Tabachnick and Fidell (2007, p. 80) note that small departures from normality of approximately this size do not appreciably bias statistics.

Inspection of the standardized residuals for all of the hypothesized relationships did not reveal heteroscedasticity of data.

SAT Math and Verbal scores had a mild positive correlation $(\mathrm{N}=3,821, \mathrm{r}=0.406$, $p<0.0005)$. Correlations between SPWB subscales ranged from 0.319 (PR-AU) to 0.688 (SA-EM; for all inter-subscale correlations, $p<0.0005$; $\mathrm{N}$ ranged from 3,734 to 3,776 due to listwise deletion). Table 1 summarizes the subscale correlations.

\section{Reliability}

Cronbach's alpha for the SPWB subscales calculated to the following: AU, 0.774; EM, 0.771; PG, 0.736; PL, 0.776; PR, 0.808.

Table 1 SPWB intercorrelations

\begin{tabular}{llllll}
\hline & AU & EM & PG & PR & PL \\
\hline EM & 0.438 & & & & \\
PG & 0.407 & 0.529 & & \\
PR & 0.319 & 0.561 & 0.546 & 0.526 & \\
PL & 0.347 & 0.614 & 0.606 & 0.582 \\
SA & 0.453 & 0.688 & 0.559 & &
\end{tabular}




\section{Exploratory Analyses}

No statistically significant SAT component score interactions were observed ( $p>0.05$ ); these interactions were removed from the regression equations in tests of hypotheses.

Gender interactions with all SAT component scores (or their squares) were not found to be statistically significant $(p>0.05)$, and were removed from the regression equations in tests of hypotheses. Several gender differences were observed in SPWB subscale scores. Women had significantly lower AU scores (standardized coefficient $=-0.072$, $p<0.0005, R_{\Delta}^{2}=0.004$ ), but higher EM (standardized coefficient: 0.054, $p<0.005$, $R_{\Delta}^{2}=0.002$ ) and PL, PR, and PG scores (standardized coefficients: 0.187, 0.193, and 0.189 , respectively; $R_{\Delta}^{2}=0.032,0.034$, and 0.033 , respectively; $p<0.0005$ for all three coefficients).

\section{Hypotheses}

See Table 2 for $F$ ratios, standardized coefficients (the standard deviation change in the dependent variable for every standard deviation increase in the predictor) for SAT component scores (and squared scores in the case of hypothesis 5) for each SPWB subscale, and their probabilities. None of the current study's hypotheses using only SAT component scores exceeded $2.0 \%$ of explained variance, reflected in the small semi-partial correlations between each component score and dimension of PWB (Table 3): semi-partial correlations represent the percentage of unique SPWB subscale variance for which each component score accounts.

H1: Multiple regression analysis revealed that SAT Math and SAT Verbal component scores predicted $A U$ subscale scores $\left(F_{2,3785}=4.804, p<0.01, R^{2}=0.003\right)$. Exploratory analyses revealed that the standardized regression coefficient for SAT Math was negative, but positive for SAT Verbal. Thus, hypothesis 1 was generally not supported, as one standardized coefficient was positive (as predicted), but the other, contrary to expectations, was negative.

Table 2 Statistical tests and standardized coefficients of hypotheses

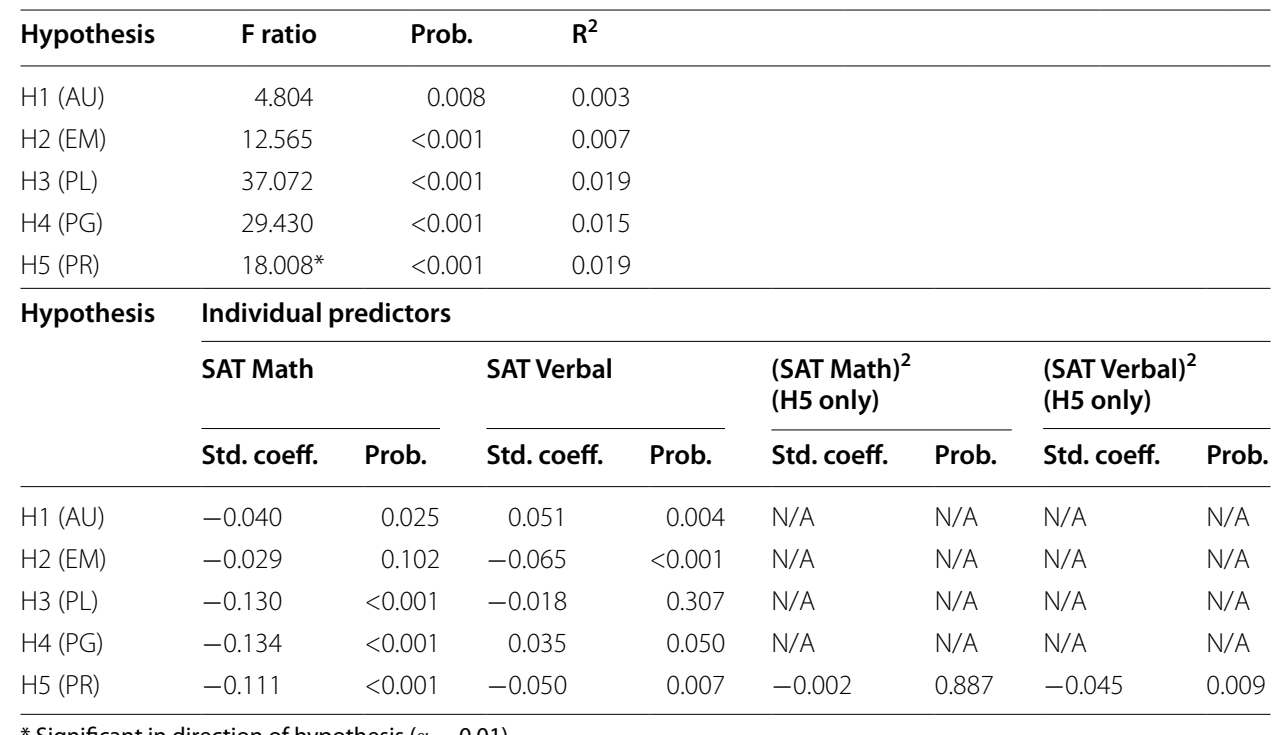

* Significant in direction of hypothesis $(\alpha=0.01)$ 
Table 3 Squared semi-partial correlations of predictors

\begin{tabular}{lllll}
\hline Hypothesis & SAT Math & SAT Verbal & (SAT Math) $^{\mathbf{2}}$ (H5 only) & (SAT Verbal) $^{\mathbf{2}}$ (H5 only) \\
\hline H1 (AU) & 0.0013 & 0.0022 & $\mathrm{~N} / \mathrm{A}$ & $\mathrm{N} / \mathrm{A}$ \\
$\mathrm{H} 2(\mathrm{EM})$ & 0.0007 & 0.0035 & $\mathrm{~N} / \mathrm{A}$ & $\mathrm{N} / \mathrm{A}$ \\
$\mathrm{H} 3(\mathrm{PL})$ & 0.0142 & 0.0003 & $\mathrm{~N} / \mathrm{A}$ & $\mathrm{N} / \mathrm{A}$ \\
$\mathrm{H} 4(\mathrm{PG})$ & 0.0151 & 0.0010 & $\mathrm{~N} / \mathrm{A}$ & $\mathrm{N} / \mathrm{A}$ \\
H5 (PR) & 0.0092 & 0.0019 & $<0.0001$ & 0.0018 \\
\hline
\end{tabular}

H2: Multiple regression analysis revealed that SAT Math and SAT Verbal component scores significantly predicted EM subscale scores $\left(F_{2,3787}=12.565, p<0.01\right.$, $\left.R^{2}=0.007\right)$. Both SAT Math and Verbal had negative standardized coefficients. Thus, hypothesis 2 was not supported, because the relationships observed were negative rather than positive. However, neither SAT Verbal nor its square was a signifcant predictor of Environmental Mastery in further exploratory analysis after controlling for Positive Relations with Others and another exploratory analysis which excluding an apparently social item from the former.

H3: Multiple regression analysis revealed that SAT Math and SAT Verbal component scores significantly predicted PL subscale scores $\left(F_{2,3792}=37.072, p<0.01\right.$, $\left.R^{2}=0.019\right)$. Both SAT Math and Verbal scores had negative standardized coefficients. Hypothesis 3 was thus not supported, as the relationship between SAT component scores and PL was negative.

H4 (PG): Multiple regression analysis revealed that SAT Math and SAT Verbal component scores significantly predicted PG subscale scores $\left(F_{2,3751}=29.430\right.$, $\left.p<0.01, R^{2}=0.015\right)$. Exploratory analyses revealed that the standardized regression coefficient for SAT Math was negative, but was positive (though nonsignificant) for SAT Verbal. Thus, hypothesis 4 was not supported, because the significant relationship was negative.

H5: Prior to conducting multiple regression analysis to test the quadratic term, both SAT Math and SAT Verbal scores were centered. Squares of these variables were then created and entered into the analysis along with the centered component scores. Multiple regression analysis revealed that centered SAT Math and SAT Verbal scores and their squares significantly predicted PR scores $\left(F_{4,3783}=18.008\right.$, $\left.p<0.01, R^{2}=0.019\right)$. All predictors had negative standardized coefficients; three, Math, Verbal, and squared Verbal, were significant, suggesting a curvilinear relationship unlikely to have arisen by chance. Thus, hypothesis 5 was supported.

Additionally, Hollingworth's suggested cut-point for social difficulty as the 99.9th percentile of IQ at the Positive Relations for Others was not supported by visual analysis of the data. Instead, visual inspection of scatterplots suggested "risk areas" for PR (in which PR scores appeared to trend downward from the remaining SAT score ranges) above approximately 1.5 standard deviations above the mean (94th percentile), and below the mean (50th SAT percentile) of SAT component scores. 


\section{Discussion}

Prior studies suggested that in children and adolescents, intelligence is generally positively related to PWB, but may have a negative curvilinear relationship to Ryff's Positive Relations with Others dimension. In adults, theory suggested generally positive relationships between PWB and intelligence, but possibly a curvilinear relationship with Positive Relations with Others. This study addressed the relationship between these constructs in young adults. Contrary to expectations, the relationship between intelligence and PWB in young adults in this study was found to be somewhat negative.

\section{SAT Verbal}

Each indicator of intelligence correlated with PWB in different ways. Such differences in how SAT Math and SAT Verbal scores relate to dimensions of PWB are of special significance to research into intelligence. Because verbal ability is one of the most robust predictors of general intelligence, bivariate correlations and standardized coefficients between SAT Verbal and dimensions of PWB likely reflect the latter's relationships to general intelligence. Recall that SAT Verbal had a positive bivariate correlation with Autonomy $(\mathrm{p}<0.05)$ and significant negative bivariate correlations with Environmental Mastery, Positive Relations with Others, and Purpose in Life. Only the standardized SAT Verbal coefficients for Environmental Mastery and Autonomy were significant $(\alpha=0.05)$, but SAT Verbal squared was a significant predictor of Positive Relations with Others.

Recall that EM scores were not predicted by SAT Verbal after controlling for PR scores, meaning that the covariance between Environmental Mastery that was accounted for by its relationship with SAT Verbal was not statistically significant after controlling for its relationship with Positive Relations with Others. Put another way, most of the variance shared between SAT Verbal with Environmental Mastery is also shared by Positive Relations with Others. Indeed, controlling for SAT Verbal scores, the EM subscale remained related to PR. This might suggest that the portion of verbal ability, and likely overall intelligence, negatively related to Environmental Mastery is social in nature, which could mean that the more intelligent a person is, the greater challenges the social challenges in their environment.

Finally, SAT Verbal also had opposite relationships with Autonomy (positive) and Positive Relations with Others (negative curvilinear), which suggests that the two constructs would be somewhat more strongly correlated if their relationship with SAT Verbal were accounted for. These relationships, based on self-report, parallel Geake and Gross's (2004) findings that teachers perceived high intellectual ability in their students as negatively correlated with the students' social functioning and conformity. Geake and Gross theorized that this relationship can be explained by evolutionary psychology. Individuals with superior language ability would be generally be viewed with mistrust, as their ability could "affect, manipulate, exploit, or even distort the group's social relationships". This theory may also be sufficient to explain the relationships between Environmental Mastery and Positive Relations with Others and SAT Verbal in this study. Although higher intelligence might allow a greater ability to attract friends and influence one's environment (increasing these latter PWB dimensions), the reactions to intelligence by group members may be more than enough to counteract these effects. Furthermore, such a 
trend would be more expected for the square of scores of verbal ability, as higher verbal ability becomes more salient to members of the group.

Other explanations for this phenomenon may be more parsimonious, however. For example, the more intelligent a student is, the more likely it is that cultural stereotypes of the social problems and lack of environmental mastery in intelligent people (e.g., "the absent-minded professor") become internalized by that student. Second, in elementary and secondary school, educational interventions for intelligent students, such as gradeor subject-acceleration ("skipping") are underutilized (cf. Colangelo et al. 2004). This would lead to less interaction with students of similar cognitive speed and content (e.g., their intelligent agemates, or older students), thus leading the more intelligent to feel isolated, as suggested by Hollingworth, and thus to have a lower overall level of Positive Relations with Others. Furthermore, this lack of challenge could cause students to feel out of control of their educational environment (likely one of the most salient environments for such students). Either explanation could be viewed as hopeful news for brighter students as they meet new people in college, since they are likely to meet those of similar intelligence levels, and who are counterexamples to the stereotype.

\section{SAT Math}

SAT Math scores related negatively to all dimensions of PWB, both in terms of bivariate correlations and standardized coefficients (controlling for their SAT Math's relationship to SAT Verbal). Four bivariate correlations were statistically significant at an alpha of 0.05 , as were three standardized coefficients: PL, PG, and PR. While more research is needed to investigate whether SAT Math consistently relates negatively to these three dimensions in particular, the following three hypotheses are proposed for this effect.

The first hypothesis is that students with high mathematical ability, in pursuit of lucrative fields such as finance or engineering, take advanced high school mathematical courses associated with these fields, to the exclusion of liberal arts classes, such as literature and philosophy. Such classes may nurture reflection about one's "goals, intentions, [and] a sense of directedness" (Ryff's Purpose in Life) and "one's potential...to grow and expand as a person" (Personal Growth). Exposure to others' ideas and worldviews in such classes may provide additional perspectives with which to understand others, potentially improving their Positive Relations with Others. Students with high mathematical ability may be less likely to have the opportunity brought by these classes to increase these dimensions. This hypothesis is generally compatible with Luthar et al's (1992) discussion of schemas and how they may moderate the relationship between intelligence and psychosocial adjustment. Students of high mathematical ability, though generally more able to create schemas when properly nurtured, are less likely to take those classes which provide this opportunity for growth.

An alternative hypothesis is that mathematical ability is positively related to metacognition, which could mean that individuals high in mathematical ability are able to perceive, and therefore report, their own deficits in these three dimensions of PWB (Kruger and Dunning 1999). Metacognition may influence well-being in those with higher mathematical ability, but not verbal ability, for two reasons. First, one's metacognition about these dimensions may simply be more closely related to his or her mathematical ability than verbal ability. Alternatively, verbal ability may allow for the articulation and 
justification of one's long-term direction in life (cf. Henriques 2003). Thus, while high verbal ability increases metacognition, and thus indirectly creates lower levels of these PWB dimensions, this high verbal ability may directly increase these same dimensions of PWB via justification. This hypothesis is also compatible with Luthar et al's schemamediation hypothesis about the relationship between intelligence and psychosocial adjustment, if verbal ability is directly tied to schema development.

A third hypothesis is that individuals with higher SAT Math scores are differentially reinforced for intellectual, "thinking" responses rather than affective responses to stressors (e.g., problem-solving). This may also account for squared SAT Verbal's relationships with Positive Relations with Others and Environmental Mastery. This hypothesis could also be compatible with Luthar et al's schema-mediation hypothesis, if it can be shown that higher intelligence not only directly benefits schema-creation, but also the creation of environmental contingencies which hinder the development of affective schemas.

\section{Limitations}

There are several limitations to the present study; some limitations are statistical in nature. One such limitation is the observed ceiling effect of the SPWB subscales. If greater variability in response options had been allowed (e.g., 10 response options rather than 6), stronger relationships between SPWB subscale scores and SAT component scores may have been observed. Responses that might otherwise have exceeded these ranges are attenuated, reducing the overall variance in the scores and thus systematically reducing the covariance between these variables. Although extrapolating below this point could lead to incorrect conclusions about the data pattern, visual analysis showed more maximum scores in the middle of SAT component score ranges. This suggests that if greater response variability were allowed, stronger relationships between SPWB subscales and SAT component scores may have been discovered.

Another limitation is generalizability. Students in the sample chose to take the SAT and attend the aforementioned university: their SAT scores may not have been high enough to attend a more selective institution. Highly intelligent students, expected to have both high SAT Math and Verbal scores, are less likely to be found in this sample than at more selective schools. Nationally, the College Board (2011) normed the SAT with a mean of 500 and a standard deviation of 110 for the Math and for the Verbal portions of the test; as such, $2.5 \%$ of students should score at or above 720 on the Math section, and $2.5 \%$ of students should score at or above 720 on the Verbal section. On the Math section in this sample, $0.8 \%$ of students scored at or above $720 ; 1.2 \%$ scored above this on the Verbal section. If more of such students were included in the sample, a higher correlation between SAT Math and Verbal may have been observed due to a lessrestricted range of scores in accepted students. Also, a different relationship between SAT scores and PWB dimensions may have been observed in data analysis, including significant interactions between SAT component scores. The low-stakes testing condition for the SPWB, taken just prior to the students' first classes, may have limited these students' generalizability.

Additionally, given that more highly selective institutions can select the most promising students with very high SAT scores, those students with such scores who instead enrolled in the university in this study may have done so systematically. Such students 
may have been less involved in extracurricular activities, had lower high school grades, written lower-quality essays, chosen a lighter financial burden, avoided pressure to succeed, or simply been less interested in attending a more selective institution. Any of these possibilities would indicate that such students are not representative of the population of highly intelligent students, and may have created a different PWB profile from another postsecondary school's students. Moreover, students in this sample were assessed just before they had started classes, which may have affected self-reported PWB.

More broadly, the young adults in this population were all incoming first-year college students. Certainly, not every young adult with intelligence above the mean attends college. Therefore, at a minimum, any inferences from the results of this study are limited to young adults who attend institutions of higher education, and may not directly generalize to the population of young adults as a whole. The relationships between intelligence and the dimensions of well-being observed in this study may not be applicable to young adults who instead directly enter the workforce, volunteer, etc.

Finally, an assumption about both the SAT and SPWB scores is that the constructs underlying them (latent scholastic aptitude and PWB dimensions) were measured without error. Structural equation modeling (SEM) could have been used to correct for measurement error (e.g., DeShon 1998) of SAT and SPWB scores.

This study also has limitations specific to the constructs under investigation beyond purely statistical concerns. One such limitation lies in Ryff's conceptualization of PWB relative to how other theorists have defined it. This study investigated Ryff's dimensions of PWB, in addition to using a version of Ryff's instrument to measure them. This study's findings are limited to Ryff's conceptualization of PWB, possibly to the exclusion of others. Methodologically, findings should be tempered by the self-report nature of the PWB instrument as well as the stress of taking it the day before classes and soon after many of the students moved to campus for the first time.

Another limitation is the relationship between the construct of intelligence and SAT scores. The relationships observed in this study could reflect another construct influencing SAT scores, such as motivation. One's level of motivation to perform well on the SAT seems related to PWB dimensions, e.g., Environmental Mastery. Thus, it is possible that the relationships between SAT and these dimensions are not solely attributable to intelligence, but rather to motivation, preparation, etc., or a combination. For example, the observed negative relationship between SAT Verbal scores and the EM subscale score could be a reflection of motivation, in that students who felt that they had poorer environmental mastery would prepare more for, and try harder on, the SAT. If such additional effort and preparation were more likely to improve Verbal scores than Math, then a relationship could be observed for the former but not the latter: a plausible explanation for that very finding in this study.

Finally, due to lack of experimental control, this study does not attribute causality to the observed relationships. There many possible reasons for a relationship between intelligence and these dimensions of PWB. For example, it is conceivable that childhood PWB not only predicts adult PWB, but also affects the course of neurological development, which in turn promotes either increased or decreased intelligence. In this case, childhood PWB would cause both adult PWB and intelligence level. Alternatively, 
neurological differences (e.g., in gray matter and white matter) may cause both increased intelligence and differences in PWB.

\section{Recommendations for Future Research}

The relationship between intelligence and PWB in young adults in this study was somewhat negative in this sample, inconsistent with findings from previous studies of adolescents and children. This may be due to the developmental differences between young adults versus adolescents and children. Additional studies on large samples of adolescents are recommended. Further research is also recommended to compare wellbeing and intelligence levels in young adults as they progress through the transitions of increasing independence that comes with adulthood. This independence could be expected to increase an individuals' well-being, but the extent to which this is moderated by an individual's intelligence level is unclear.

Additional research into other factors affecting PWB, such as gender (which explained less than $4 \%$ of the variance in this study) is needed. Personality factors (Abbott et al. 2008), life events such as cancer survival (Costanzo et al. 2009), and stress (Chang 2006) have recently been shown to account for variance in PWB dimensions to varying degrees (12.5-19.8, 0-1.5, and 9-50\%, respectively-Abbott et al. studied future PWB levels). Future research may reveal that the role of intelligence in PWB is trivial or nonsignificant after controlling for such factors.

Prior researcher has uncovered linear relationships between intelligence and many constructs and outcomes. However, the significant curvilinear relationship between SAT Verbal and Positive Relations with Others in this study demonstrates the importance of investigating polynomial models when warranted by the literature. To the extent that this relationship is replicated in future studies, it is recommended that polynomial relationships of intelligence with other variables be considered in future studies of intelligence.

Procedural considerations are also important when studying extreme intelligence levels. Depending on sample size, individuals at least two and a half to three standard deviations above the mean of a sample may be treated as univariate outliers. Such individuals, however, are likely to be more highly influential in statistical tests of polynomial relationships than in linear relationships. Therefore, unless there are other reasons to warrant excluding such an individual's data (e.g., a nonsensical pattern of responses, a high score on a lie scale, or anything else indicating a reason to believe the data are not to be trusted), automatic exclusion of such individuals is not recommended.

The extent to which inferences can be made statistical analyses about the population of individuals with such high intelligence (such as those above Hollingworth's suggested 99.9th percentile cutoff) is debatable. Such individuals are likely to be the highest intelligence score in all but very large samples. In the absence of data points above this point, the best-fitting regression line or curve ends at about their score (if not excluded as an outlier!). Additionally, since the development of invariance studies, few studies have been conducted on the invariance of constructs like PWB at different ranges of intelligence. Much validity evidence about intelligence may thus be inapplicable to people with very high intelligence scores. This could lead to inferences about the relationship between intelligence and other variables which may not apply to these individuals. Such inferences may be dubious at relatively low levels (in this study, evidence from 
scatterplots of a curvilinear pattern emerged at the 95th percentile). Invariance studies of intelligence are therefore recommended, as are mixed-methods approaches for those of rarified ability.

\section{Conclusion}

This study revealed that for the sample of young adults, more intelligent students were, the lower their PWB tended to be four of the five tested dimensions. The extent to which other factors, such as personality and or gender, interact with intelligence in its relationship to PWB, is a subject rich in potential future study. Because childhood intelligence has proven to be a positive predictor of later occupational status, and adulthood intelligence of current occupational status (e.g., Judge et al. 1999), it seems likely that the more intelligent young adults are, the greater likelihood that they can develop into the most productive and influential members of society, yet without considering other factors such as PWB, such efforts may be incomplete.

Winner (2000) promotes the "interven[tion] for the happiness and health of gifted students" lest they become "bored" and "socially isolated", and so that "they can become our future leaders and innovators". The negative relationship found in this study between intelligence and the Positive Relations with Others dimension of PWB lends credence to especially targeting such efforts toward highly gifted students. Research into effective interventions into PWB for such students, as well as how they may be tailored in order to account for possible interactive effects of development, gender, or personality, could ultimately improve the lives of these individuals with great potential to success and improve the world.

\section{Endnotes}

at the time of the original Stanford-Binet (Terman's translation and revision to Binet's test, or S-B), no method had yet been discovered to transform S-B scores, given in the form of ratio IQ (100 times mental age divided by chronological age), into deviation IQ scores. Therefore, Terman's (1925) and Hollingworth's (1942) findings will be reported in the context of the original S-B score, whereas other scores will be related to percentiles.

b $140+$ IQ on the original (ratio IQ) S-B.

c $136+$ IQ (deviation; mean $=100$, standard deviation $=15$ ).

d 136-140 (deviation) IQ, whom Gallucci called "moderately superior."

e $150+$ (deviation) IQ, whom Gallucci called "very superior."

${ }^{\mathrm{f}} 127+$ (deviation) IQ.

g Over 160 IQ, original S-B.

h Hollingworth's reasoning on this matter reflects thinking in terms of deviation IQ (i.e., that highly intelligent children deviate in the extreme from the norms of their agemates in their cognitive content, which, in her view, creates an effect in non-cognitive domains). Therefore, her theory relates to deviation IQ, though the subjects of her study were more technically measured using a ratio IQ scale.

${ }^{\mathrm{i}}$ Deviation IQ of at least 145 (99.75th percentile).

j $160+$ deviation IQ.

k 116-132 deviation IQ.

${ }^{1} 132+\mathrm{IQ}$.

m 140+ IQ. 
Author contributions

CJW and GRH designed the study. GRH and CJW incorporated theoretical perspectives to the study. CJW carried out the statistical analysis. CJW and GRH drafted the manuscript. All authors read and approved the final manuscript.

\section{Acknowledgements}

The authors would like to thank Profs. Robin Anderson and Dena Pastor for their comments on previous versions of this article.

\section{Compliance with ethical guidelines}

Competing interests

The authors declare that they have no competing interests.

Received: 24 November 2014 Accepted: 14 May 2015

Published online: 26 July 2015

\section{References}

Abbott, R. A., Croudace, T. J., Ploubidis, G. B., Kuh, D., Richards, M., \& Huppert, F. A. (2008). The relationship between early personality and midlife psychological well-being: evidence from a UK birth cohort study. Journal Social Psychiatry and Psychiatric Epidemiology, 43, 679-687.

Achenbach, T. M. (1991). Manual for the Child Behavior Checklist/4-18 \& 1991 Profile. Burlington: University of Vermont, Department of Psychiatry.

American Psychiatric Association. (200). Diagnostic and statistical manual of mental disorders (4th ed., text revision). Washington, DC: Author.

Astin, A. W., \& Astin, H. S. (2010). Exploring and nurturing the spiritual life of college students. Journal of College and Character, 11(3), 1-9.

Betts, G. T. (1986). Development of the emotional and social needs of gifted individuals. Journal of Counseling and Development, 64, 587-589.

Bilder, R. M., Reiter, G., Bates, J., Lencz, T., Szeszko, P., Goldman, R. S., et al. (2006). Cognitive development in schizophrenia: follow-back from the first episode. Journal of Clinical and Experimental Neuropsychology, 28(2), 270-282.

Bland, L., \& Sowa, C. (1994). An overview of resilience in gifted children. Roeper Review, 17(2), 77-80.

Chang, E. C. (2006). Perfectionism and dimensions of Psychological Well-Being in a college student sample: a test of a stress-mediation model. Journal of Social and Clinical Psychology, 25(9), 1001-1022.

The College Board (1926-2005). SAT Reasoning Test. New York: The College Board.

Costanzo, E. S., Ryff, C. D., \& Singer, B. H. (2009). Psychosocial adjustment among cancer survivors: findings from a national survey of health and well-being. Health Psychology, 28(2), 147-156.

Dauber, S. L., \& Benbow, C. P. (1990). Aspects of personality and peer relations of extremely talented adolescents. Gifted Child Quarterly, 34(1), 10-14.

Davis, G. A., \& Rimm, S. B. (2004). Education of the gifted and talented (5th ed.). Boston: Allyn and Bacon.

DeShon, R. P. (1998). A cautionary note on measurement error corrections in structural equation models. Psychological Methods, 3(4), 412-423.

Frey, M. C., \& Detterman, D. K. (2004). Scholastic assessment or g? The relationship between the scholastic assessment test and general cognitive ability. Psychological Science, 15(6), 373-378.

Gallucci, N. T. (1988). Emotional adjustment of gifted children. Gifted Child Quarterly, 32, 273-276.

Gottfredson, L. S. (2008). Of what value is intelligence? In A. Prifitera, D. H. Saklofske, \& L. G. Weiss (Eds.), WISC-IV clinical assessment and intervention (2nd ed., pp. 545-563). Amsterdam: Elsevier.

Gross, M. U. M. (2004). The use of radical acceleration in cases of extreme intellectual precocity. Grouping and acceleration practices in gifted education (pp. 13-31). Thousand Oaks: Corwin Press. Retrieved November 7, 2007, from PsycINFO database.

Grossberg, I. N., \& Cornell, D. G. (1988). Relationship between personality adjustment and high intelligence: terman versus Hollingworth. Exceptional Children, 55(3), 266-272.

Henriques, G. (2003). The tree of knowledge system and the theoretical unification of psychology. Review of General Psychology, 7(2), 150-182. Retrieved October 17, 2007, from PsycINFO database.

Hollingworth, L. S. (1942). Children above 180 IQ Stanford-Binet: origin and development. Yonkers-on-Hudson: World Book.

Judge, T. A., Higgins, C. A., Thoresen, C. J., \& Barrick, M. R. (1999). The big five personality traits, general mental ability, and career success across the life span. Personnel Psychology, 52(3), 621-652.

Kaliski, P. K. (2006). Diagnosing the misfit of the theoretical factor structure of the Scales of Psychological Well-Being (SPWB): Development of the revised SPWB. Unpublished master's thesis, James Madison University, Harrisonburg, Virginia, USA.

Kline, B. E., \& Meckstroth, E. A. (1985). Understanding and encouraging the exceptionally gifted. Roeper Review, 8(1), 24-30

Kruger, J., \& Dunning, D. (1999). Unskilled and unaware of it: how difficulties in recognizing one's own incompetence lead to inflated self-assessments. Journal of Personality and Social Psychology, 77(6), 1121-1134.

Lindfors, P., Berntsson, L., \& Lundberg, Ulf. (2006). Factor structure of Ryff's psychological well-being scales in Swedish female and male white-collar workers. Personality and Individual Differences, 40, 1213-1222.

Lovecky, D. V. (1986). Can you hear the flowers singing? Issues for gifted adults. Journal of Counseling and Development, 64, 572-575.

Luthar, S. S., Zigler, E., \& Goldstein, D. (1992). Psychosocial adjustment among intellectually gifted adolescents: the role of cognitive-developmental and experiential factors. Journal of Child Psychology and Psychiatry, 33(2), 361-375. 
Lysaker, P. H., Clements, C. A., Wright, D. E., Evans, J., \& Marks, K. A. (2001). Neurocognitive correlates of helplessness, hopelessness, and well-being in schizophrenia. The Journal of Nervous and Mental Disease, 189(7), 457-462.

MacCallum, R. C., Zhang, S., Preacher, K. J., \& Rucker, D. D. (2002). On the practice of dichotomization of quantitative variables. Psychological Methods, 7(1), 19-40.

Neihart, M. (1999). The impact of giftedness on psychological well-being. Roeper Review., 22(1), 10-17.

Norman, A. D., Ramsay, S. G., \& Martray, C. R. (1999). Relationship between levels of giftedness and psychosocial adjustment. Roeper Review, 22(1), 5-9.

Parker, J., Mitchell, A., Kalpakidou, A., Walshe, M., Jung, H.-Y., Nosarti, C., et al. (2008). Cerebellar growth and behavioural and neuropsychological outcome in preterm adolescents. Brain, 131, 1344-1351.

Peterson, R. A. (1994). A meta-analysis of Cronbach's coefficient alpha. Journal of Consumer Research, 21(2), 381-391.

Plescia-Pikus, M., Long-Suter, E., \& Wilson, J. P. (1988). Achievement, well-being, intelligence, and stress reaction in adult children of alcoholics. Psychological Reports, 62, 603-609.

Reynolds, C. R., \& Kamphaus, R. W. (1992). Behavior assessment system for children-Second Edition-Student Observation System (BASC-2-SOS). Circle Pines: AGS/American Guidance Service.

Richards, J., Encel, J., \& Shute, R. (2003). December). The emotional and behavioural adjustment of intellectually gifted adolescents: a multi-dimensional, multi-informant approach. High Ability Studies, 14(2), 153-164.

Rinn, A. N., \& Plucker, J. A. (2004). We recruit them, but then what? The educational and psychological experiences of academically talented undergraduates. Gifted Child Quarterly, 48(1), 54-67.

Ryff, C. (1989). Happiness is everything, or is it? Explorations on the meaning of Psychological Well-Being. Journal of Personality and Social Psychology, 57(6), 1069-1081.

Sarason, I. G., Levine, H. M., Basham, R. B., \& Sarason, B. R. (1983). Assessing social support: the social support questionnaire. Journal of Personality and Social Psychology, 44, 127-139.

Seligman, M. E. P., \& Csikszentmihalyi, M. (2000). Positive psychology: an introduction. American Psychologist, 55(1), 5-14.

Springer, K. W., \& Hauser, R. M. (2006). An assessment of the construct validity of Ryff's Scales of Psychological Well-Being: method, mode, and measurement effects. Social Science Research, 35(4), 1080-1102.

Strauser, D. R., Lustig, D. C., \& Çiftçi, A. (2008). Psychological Well-Being: its relation to work personality, vocational identity, and career thoughts. The Journal of Psychology, 142(1), 21-35.

Tabachnick, B. G., \& Fidell, L. S. (2007). Using multivariate statistics (5th ed.). Boston: Allyn and Bacon.

Terman, L. M. (1925). Genetic studies of genius, Vol. 1: Mental and physical traits of a thousand gifted children. Stanford: Stanford University Press.

The College Board (2011). SAT Data Tables. Retrieved June 23, 2011, from http://professionals.collegeboard.com/testing/ sat-reasoning/scores/sat-data-tables.

Torrance, E. P. (1962). Guiding creative talent. Englewood Cliffs: Prentice-Hall.

Van Dierendonck, D. (2004). The construct validity of Ryff's Scales of Psychological Well-being and its extension with spiritual well-being. Personality and Individual Differences, 36(3), 629-643.

Vialle, W., Heaven, P. C. L., \& Ciarocchi, J. (2007). On being gifted, but sad and misunderstood: social, emotional, and academic outcomes of gifted students in the Wollongong Youth Study. Educational Research and Evaluation, 13(6), 569-586.

Watson, D., \& Clark, L. A. (1991). Preliminary manual for the Positive and Negative Affect Schedule-Expanded Form (PANAS-X). Unpublished manuscript, Southern Methodist University, Dallas, TX.

Winner, E. (2000). The origins and ends of giftedness. American Psychologist, 55(1), 159-169.

\section{Submit your manuscript to a SpringerOpen ${ }^{\circ}$ journal and benefit from:}

- Convenient online submission

- Rigorous peer review

- Immediate publication on acceptance

- Open access: articles freely available online

- High visibility within the field

- Retaining the copyright to your article

Submit your next manuscript at $\boldsymbol{s p r i n g e r o p e n . c o m ~}$ 